\title{
ALGUNS ASPECTOS SOBRE A SITUAÇÃO JURÍDICA DO NÃO NACIONAL NO BRASIL: Da Lei do Estrangeiro à Nova Lei de Migração
}

\author{
Sidney Guerra \\ Pós-doutor pelo Centro de Estudos Sociais da Universi- \\ dade de Coimbra; PÓS-doutor pelo Programa Avançado \\ em Cultura Contemporânea da Universidade Federal do \\ Rio de Janeiro (UFRJ). Professor associado da Univer- \\ sidade Federal do Rio de Janeiro. Presidente do Instituto \\ Brasileiro Pacificador (IBP). Advogado no Rio de Janeiro. \\ sidneyguerra@terra.com.br
}

Recebido em: 12/7/2017

Aceito em: 3/8/2017

\section{Resumo}

0 fenômeno migratório, embora não seja recente, tem produzido vários desdobramentos no plano estatal, seja no campo político, social, econômico e jurídico. No Brasil, a matéria sobre a situação jurídica do estrangeiro estava concebida numa lei criada no período da ditadura militar, cuja lógica estava alicerçada na segurança nacional. Este cenário, todavia, foi modificado ao ser publicada a Lei 13.445/2017, que contemplou a Lei de Migração no Brasil, ancorada na proteção dos direitos humanos.

\section{Palavras-chave}

Estrangeiro. Migração. Direitos humanos

\section{SOME ASPECTS ABOUT THE LEGAL SITUATION OF THE NON-NATIONAL IN BRAZIL: FROM THE LAW OF THE FOREIGNER TO THE NEW LAW OF MIGRATION}

Abstract:

The migratory phenomenon, although not recent, has produced many unfoldings at the state level, be it in the political, social, economic and juridical field. In Brazil, the subject about the legal situation of the foreigner was conceived in a law created during the period of the military dictatorship, whose logic was based on national security. However, this scenario was modified when the Law 13.445/2017 was published, which contemplated the Migration Law in Brazil, anchored in the protection of human rights.

\section{Keywords}

Foreign. Migration. Human rights

\section{Sumário}

1 Introdução. 2 Nacionalidade, estrangeiro e o migrante. 30 não nacional no Brasil: da lei do estrangeiro para a nova lei de migração. 4 A admissão e a retirada compulsória do migrante. 5 Considerações finais. 6 Referências. 


\section{INTRODUÇÃO}

A mobilidade humana assume contornos complexos na atualidade e alcança o impressionante número de mais de 244 milhóes de pessoas que se encontram fora do seu país de origem, ou seja, mais de 3,4\% da população mundial, segundo dados da Organização das Naçôes Unidas (ONU) referentes ao ano de 2015. ${ }^{1}$

Sendo um fenômeno de grande repercussão para o Estado, com desdobramentos nos campos social, político, econômico, cultural e outros, a matéria ganha relevo, com vários aspectos que precisam ser regulados pelo Direito.

No Brasil, até a edição da Lei 13.445, de 24 de maio de 2017, a matéria relativa à situação jurídica do estrangeiro estava prevista na Lei n. 6.815, de 19 de agosto de 1980, não havendo, até aquele momento, uma lei que tratasse de maneira específica sobre as migrações.

Frise-se, por oportuno, que a lei $6.815 / 80$ foi concebida no período em que o Estado brasileiro era conduzido por militares e levava em conta aspectos voltados principalmente para a segurança nacional, apresentando-se como discriminatória e contrária aos fundamentos e princípios que norteiam a Carta Magna de 1988.

Após longos debates e estudos sobre a necessidade de conceber na ordem jurídica brasileira uma lei que retratasse a situação atual dos não nacionais, que até então eram vistos como hóspedes (estrangeiro), a matéria passou a ser regrada pela nova Lei de Migração. ${ }^{2}$

1 ASANO, Camila Lissa; TIMO, Pétalla Brandão. A nova Lei de migração no Brasil e os direitos humanos. Disponível em: <https://br.boell.org/pt-br/2017/04/17/nova-lei-de-migracao-no-brasil-e-os-direitos-humanos>. Acesso em: 3 maio 2017.

2 O texto analisado pelos senadores foi um substitutivo apresentado pela Câmara dos Deputados ao projeto original do Senado (SCD 7/2016 ao PLS 288/2013). 
A nova Lei de Migração, que chega em boa hora, foi concebida em conformidade com o sentimento constitucional ${ }^{3}$ de 1988 , que atribuiu valor à dignidade da pessoa humana e toda carga correspondente à proteção dos direitos humanos. Ela trata dos direitos e deveres do migrante e do visitante no Brasil; regula a entrada e a permanência de estrangeiros e estabelece normas de proteção ao brasileiro no exterior.

Para melhor compreensão da norma, ainda que de maneira sucinta, importante destacar alguns aspectos que até recentemente eram vigentes no Brasil, no que tange à situação jurídica do estrangeiro, transitando agora para um novo modelo, qual seja, o que consagra o migrante e o visitante. Este é o propósito do presente artigo: apresentar aspectos relativos à nova Lei de Migração brasileira, confrontando alguns pontos do já revogado Estatuto do Estrangeiro.

\section{NACIONALIDADE, ESTRANGEIRO E O MIGRANTE}

Até a vigência da Lei 6.815/80, chegava-se ao entendimento sobre quem era estrangeiro, partindo-se da identificação de quem era nacional, ou seja, o indivíduo que não se encontrava no rol descrito do artigo 12 da Constituição de 1988, seja como brasileiro nato ou naturalizado, era considerado estrangeiro e, em situaçôes excepcionais e diversas, apátrida. A matéria sobre nacionalidade vem expressa na Carta Magna de 1988 e a situação jurídica do estrangeiro encontrava-se prevista, como mencionado, na Lei 6.815/80, o conhecido Estatuto do Estrangeiro. ${ }^{4}$

3 VERDÚ, Pablo Lucas. O sentimento constitucional: aproximações ao estudo do sentir constitucional como modo de integraçáo política. Traduçáo Agassiz Almeida Filho. Rio de Janeiro: Forense, 2004: "O sentimento constitucional é expressão de uma cultura política assimilada e sentida pelas pessoas acerca dos principais alicerces jurídico-políticos de convivência, o que envolve realização de direitos fundamentais."

4 A Lei sobre Migração no Brasil - 13.445/2017 revogou a Lei 6.815/80. 
O estudo relativo à nacionalidade é comum para o Direito Constitucional com reflexos para o Direito Internacional, posto que a Lei Maior apresenta os casos dos indivíduos que possuem a nacionalidade brasileira e por exclusão os que não se encontram nesse rol se apresentavam como estrangeiros. $\mathrm{O}$ artigo $12 \mathrm{da}$ Constituição brasileira de 1988 prescreve que, in verbis:

Art. 12. São brasileiros:

I - natos: a) os nascidos na República Federativa do Brasil, ainda que de pais estrangeiros, desde que estes não estejam a serviço de seu país; b) os nascidos no estrangeiro, de pai brasileiro ou mãe brasileira, desde que qualquer deles esteja a serviço da República Federativa do Brasil; c) os nascidos no estrangeiro de pai brasileiro ou de mãe brasileira, desde que sejam registrados em repartição brasileira competente ou venham a residir na República Federativa do Brasil e optem, em qualquer tempo, depois de atingida a maioridade, pela nacionalidade brasileira;

II - naturalizados: a) os que, na forma da lei, adquiram a nacionalidade brasileira, exigidas aos originários de países de língua portuguesa apenas residência por um ano ininterrupto e idoneidade moral; b) os estrangeiros de qualquer nacionalidade, residentes na República Federativa do Brasil há mais de quinze anos ininterruptos e sem condenação penal, desde que requeiram a nacionalidade brasileira.

No campo do direito das gentes, Verdross ${ }^{6}$ destaca alguns princípios relacionados à matéria: “a) o direito das gentes confia à apreciação de cada Estado determinar como se adquire e se perde a sua nacionalidade; b) nenhum Estado pode determinar as condições de aquisição e perda de uma nacionalidade estrangeira; c) a apreciação estatal, na determinação da matéria, acha-se limitada pelo Direito Internacional; d) as limitaçóes resultam dos tratados, do costume e dos princípios gerais de Direito, universalmente reconhecidos; e) uma declaração de nacionalidade feita por um

5 Para REZEK, José Francisco Direito internacional público: curso elementar. 6. ed. São Paulo: Saraiva, 1996. p. 178, "nacionalidade é um vínculo político entre o Estado soberano e o indivíduo, que faz deste um membro da comunidade constitutiva da dimensão pessoal do Estado. Importante no âmbito do direito das gentes, esse vínculo político recebe, entretanto, uma disciplina jurídica de direito interno: a cada Estado incumbe legislar sobre sua própria nacionalidade, desde que respeitadas, no direito internacional, as regras gerais, assim como regras particulares com que acaso se tenha comprometido".

6 VERDROSS apud GUERRA, Sidney. Curso de direito internacional público. 10. ed. São Paulo: Saraiva, 2016. p. 370. 
Estado, no exercício de sua competência, tem efeitos jurídicos com relação aos demais Estados; f) não o terá, porém, se a declaração transgredir os limites impostos pelo direito das gentes; g) os Estados só podem conferir sua nacionalidade a pessoas que com eles tenham relação real e estreita, tais como a filiação e o nascimento, no seu território; h) a naturalização de um estrangeiro juridicamente capaz não poderá efetivar-se sem o seu consentimento; i) uma naturalização que não exija o consentimento dos interessados só é possível em caso de cessão territorial, quando os indivíduos tenham seu domicílio ordinário no território cedido, ressalvadas as disposiçóes convencionais em sentido oposto; j) o princípio de que a nacionalidade implica uma relação efetiva e permanente com o Estado de que é súdito acarreta, entre outras consequências, a de que as disposiçóes que fazem depender a perda da nacionalidade de uma exclusão formal da agrupação estatal são ineficazes perante o direito das gentes, se a pessoa em questáo, estabelecida permanentemente em um país estrangeiro, tiver adquirido a nacionalidade deste sem ter sido excluída da agrupação estatal anterior; k) somente em seu território tem o Estado o direito de baixar normas sobre a matéria, náo tendo qualquer valor, perante o Direito Internacional, as naturalizaçóes levadas a efeito em território ocupado por determinada potência.

O sujeito natural do Estado é o nacional, que em seu conjunto corresponde à ideia de povo, que não pode ser confundido com população por se tratar de conceito que designa o número de habitantes de um território num determinado momento. Já os estrangeiros, por exclusão, eram identificados como todos aqueles que não se enquadravam na categoria de nacionais.

A matéria, todavia, sofreu profunda mudança a partir do momento que a Lei 13.445/ 2017 entrou em vigência. A nova lei estabeleceu alteraçóes na nomenclatura do não nacional, substituindo a figura do estrangeiro pela do migrante, como se depreende da leitura do artigo $1^{\circ}$ :

"Artigo $1^{\circ}$ Esta Lei dispóe sobre os direitos e os deveres do migrante e do visitante, regula a sua entrada e estada no País e estabelece princípios e diretrizes para as políticas públicas para o emigrante.

$\$ 1^{\circ}$ Para os fins desta Lei, considera-se:

$$
\text { I - (VETADO); }
$$


II - imigrante: pessoa nacional de outro país ou apátrida que trabalha ou reside e se estabelece temporária ou definitivamente no Brasil;

III - emigrante: brasileiro que se estabelece temporária ou definitivamente no exterior;

IV - residente fronteiriço: pessoa nacional de país limítrofe ou apátrida que conserva a sua residência habitual em município fronteiriço de país vizinho;

V - visitante: pessoa nacional de outro país ou apátrida que vem ao Brasil para estadas de curta duraçáo, sem pretensão de se estabelecer temporária ou definitivamente no território nacional;

VI - apátrida: pessoa que náo seja considerada como nacional por nenhum Estado, segundo a sua legislação, nos termos da Convenção sobre o Estatuto dos Apátridas, de 1954, promulgada pelo Decreto no 4.246, de 22 de maio de 2002, ou assim reconhecida pelo Estado brasileiro.

\section{NÃO NACIONAL NO BRASIL: Da Lei do Estrangeiro para a Nova Lei de Migração}

O Senado Federal aprovou no dia 18 de abril de 2017, 7 por unanimidade, o projeto Substitutivo da Câmara dos Deputados n. 7/2016 que revoga o Estatuto do Estrangeiro, criado durante o governo militar, e instituiu a nova Lei de Migração brasileira (Lei 13.345/2017).

Indubitavelmente que a nova lei coloca o Brasil em posição de vanguarda nesta matéria, posto que defere aos imigrantes uma série de prerrogativas que até então eram conferidas apenas para os seus nacionais. Entre as principais mudanças introduzidas pela nova Lei de Migração estão a desburocratização do processo de

\footnotetext{
7 A nova Lei de Migração foi proposta pelo atual ministro das Relaçôes Exteriores, senador Aloysio Nunes, em 2013. Aprovado pelo plenário do Senado em agosto de 2015, o PLS 288/2013 seguiu para a Câmara, foi rebatizado de PL 2.516/2015 e tramitou sob relatoria do deputado Orlando Silva (PCdoB-SP), em uma Comissão Especial. Aprovado pelo plenário da Câmara em dezembro de 2016, o projeto voltou para o Senado. O novo relator designado foi o senador Tasso Jereissati (PSDB-CE), que recomendou a aprovação de um texto muito próximo ao que voltara da Câmara. A lei foi aprovada por 43 dos senadores presentes e teve quatro votos contrários e uma abstenção.
} 
regularização migratória, a institucionalização da política de vistos humanitários, a não criminalização por razóes migratórias, além de conferir uma série de direitos aos migrantes que até então não eram garantidos.

Como mencionado anteriormente, a matéria estava regrada na ordem interna pela Lei n. 6.815, de 19 de agosto de 1980, que tratava da situação jurídica do estrangeiro no Brasil. A referida lei já não atendia aos anseios do grande número de pessoas que se instalaram no Brasil, pelos mais diversos motivos, ao longo dos anos. Apenas para demonstrar a assertiva, verifica-se que atualmente existem aproximadamente 1 milhão de estrangeiros em território brasileiro, sejam eles permanentes ou transitórios, conforme gráfico a seguir: ${ }^{8}$

\section{Gráfico 1 - Estrangeiros em território brasileiro}

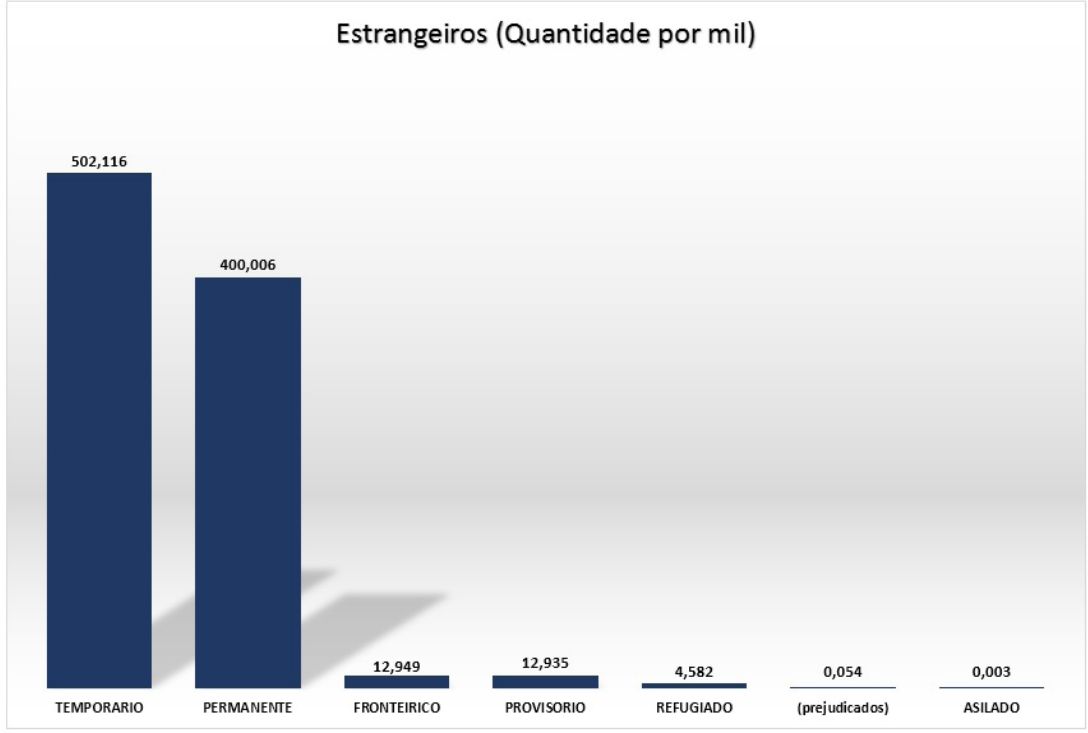

Não se pode olvidar que à época que o Estatuto foi concebido, a prioridade consagrada na legislação priorizava a segurança nacional, os interesses socioeconômicos do Brasil e o trabalhador nacional. O termo estrangeiro adotado pela norma citada indicava a existência de um indivíduo que "é natural de outro país; que não

${ }^{8}$ Disponível em: <http://www.pf.gov.br/imprensa/estatistica/estrangeiros>. Acesso em: 16 maio 2017. 
faz parte de uma família, de um grupo". O Gráfico 2 apresenta o quantitativo de estrangeiros que vieram para o Brasil nos últimos anos, conforme estudo elaborado pela Polícia Federal. ${ }^{9}$

$$
\begin{gathered}
\text { Gráfico } 2 \text { - Quantitativo de estrangeiros que vieram } \\
\text { para o Brasil nos últimos anos }
\end{gathered}
$$

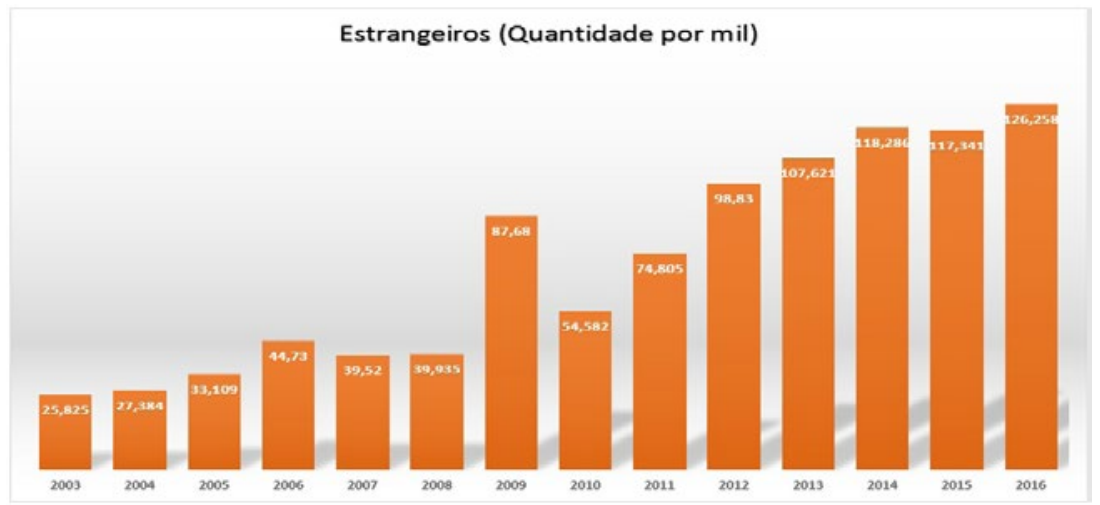

No caso da nova lei, o legislador preferiu adotar a figura do migrante e do visitante (artigo $1^{\circ}$ ), em conformidade com a política consagrada na atualidade em prol dos direitos humanos. De certo modo, o termo empregado na nova legislação faz com que o indivíduo, que não seja nacional do Estado, não se sinta estranho e preterido no local que se encontra, como se um forasteiro fosse. Aliás, o termo estrangeiro remete a esta ideia, conforme o entendimento esposado anteriormente.

Existem pessoas de várias nacionalidades distintas que se instalaram em território brasileiro, sendo certo que o número de bolivianos tem aumentado bastante nos últimos anos e encontram-se em primeiro lugar. O Gráfico $3^{10}$ apresenta este número com maior incidência de nacionalidades no Brasil:

9 Disponível em: <http://www.pf.gov.br/imprensa/estatistica/estrangeiros>. Acesso em: 16 maio 2017.

${ }^{10}$ Disponível em http://www.pf.gov.br/imprensa/estatistica/estrangeiros. Acesso em 16 de maio de 2017 
Gráfico 3 - Nacionalidades distintas que se instalaram em território brasileiro

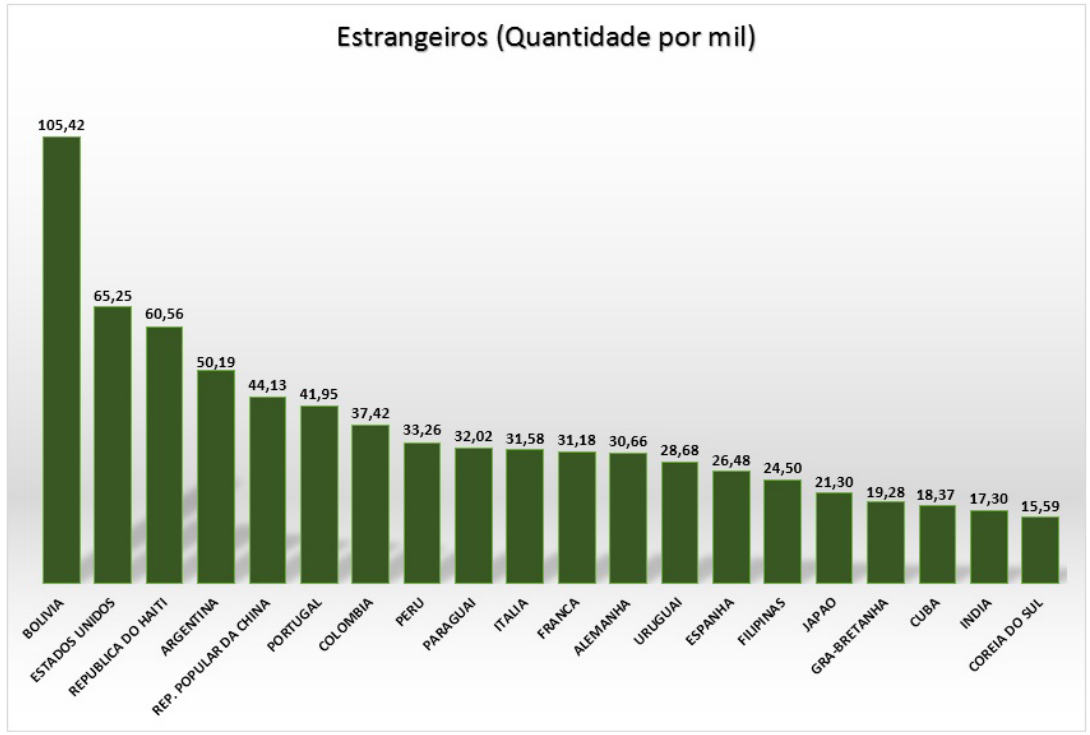

Diferentemente do Estatuto do Estrangeiro, a nova Lei de Migração trata o imigrante como um sujeito de direitos e garante em todo o território nacional, em condição de igualdade com os nacionais, uma série de direitos que anteriormente não eram concebidos, a saber: a inviolabilidade do direito à vida, à liberdade, à igualdade, à segurança e à propriedade; direitos e liberdades civis, sociais, culturais e econômicos; direito à liberdade de circulação em território nacional; direito à reunião familiar do imigrante com seu cônjuge ou companheiro e seus filhos, familiares e dependentes; medidas de proteção a vítimas e testemunhas de crimes e de violaçôes de direitos; direito de transferir recursos decorrentes de sua renda e economias pessoais a outro país, observada a legislação aplicável; direito de reunião para fins pacíficos; direito de associaçáo, inclusive sindical, para fins lícitos; acesso a serviços públicos de saúde e de assistência social e à previdência social, nos termos da lei, sem discriminação em razão da nacionalidade e da condição migratória; amplo acesso à Justiça e à assistência jurídica integral gratuita aos que comprovarem insuficiência de recursos; direito à educação pública, vedada a discriminação em razão da nacionalidade e da condição migratória; garantia de cumprimento de obrigaçôes legais e contratuais trabalhistas e de aplicação das normas de proteção ao 
trabalhador, sem discriminação em razão da nacionalidade e da condição migratória; isenção das taxas de que trata esta Lei, mediante declaração de hipossuficiência econômica, na forma de regulamento; direito de acesso à informação e garantia de confidencialidade quanto aos dados pessoais do imigrante, nos termos da Lei ${ }^{\circ}$ 12.527, de 18 de novembro de 2011; direito à abertura de conta bancária; direito de sair, de permanecer e de reingressar em território nacional, mesmo enquanto pendente pedido de residência, de prorrogação de estada ou de transformaçáo de visto em residência, e direito do imigrante de ser informado sobre as garantias que lhe são asseguradas para fins de regularização migratória.

Ademais, é permitido ao imigrante exercer cargo, emprego e função pública, conforme definido em edital, excetuados aqueles reservados para brasileiro nato, nos termos da Constituição Federal, ${ }^{11}$ não sendo exigível ao migrante prova documental impossível ou descabida que dificulte ou impeça o exercício de seus direitos, inclusive o acesso a cargo, emprego ou função pública.

Estas mudanças, que foram propostas pela nova lei, têm gerado muitas críticas por determinados setores, considerados mais conservadores, sobre as grandes possibilidades e oportunidades que passarão a ser conferidas aos indivíduos que não possuem a nacionalidade brasileira.

Com efeito, a novel legislação procura dar concretude ao que estabelece o texto constitucional brasileiro, in casu o Artigo $5^{\circ}$ que consagra o princípio da igualdade entre os brasileiros e os não brasileiros, pugnando de maneira clara o combate à discriminação, à xenofobia e outras práticas que sejam consideradas atentatórias aos direitos humanos.

Em interessante abordagem Asano e Timo ${ }^{12}$ afirmam que nos últimos quatro anos, vários debates em torno das migraçóes foram impulsionados no Brasil, principalmente pela chegada de migrantes haitianos, o que evidenciou uma série de questóes como: ausência de políticas públicas para o acolhimento, obstáculos

\footnotetext{
${ }^{11}$ Artigo 12. $\$ 3^{\text {o }}$ São privativos de brasileiro nato os cargos: I - de Presidente e Vice-Presidente da República; II - de Presidente da Câmara dos Deputados; III - de Presidente do Senado Federal; IV - de Ministro do Supremo Tribunal Federal; V - da carreira diplomática; VI - de oficial das Forças Armadas; VII - de Ministro de Estado da Defesa.

${ }^{12}$ ASANO, Camila Lissa; TIMO, Pétalla Brandão, op. cit.
} 
burocráticos para se obter documentação, discriminação e dificuldades de integração, que resultaram em vários eventos e debates públicos que culminaram ao final com a nova Lei de Migração que estivesse em conformidade com a política brasileira em prol dos direitos humanos. E no contraponto das questóes contrárias à nova legislação as autoras ${ }^{13}$ advertem que a adoção de medidas restritivas para o acesso dos migrantes em território nacional não são consideradas adequadas, pois aumentam a insegurança e adoção de mecanismos criminosos e, por isso mesmo, a nova legislação migratória precisa observar ao menos cinco propostas: “a) A garantia dos direitos humanos das pessoas migrantes, sem discriminação de nenhum tipo e independente da situação migratória; b) $\mathrm{O}$ estabelecimento de procedimentos de regularização migratória rápidos, efetivos e acessíveis como uma obrigação do Estado e um direito do migrante; c) A não criminalização das migraçóes, incluindo o princípio de não detenção do migrante por razóes vinculadas à sua situação migratória; d) O controle judicial e o acesso dos migrantes a recursos efetivos sobre todas as decisóes do poder público que possam gerar vulneração de seus direitos; e) A criação de uma instituição nacional autônoma, com um corpo profissional permanente e especializado e mecanismos de supervisão e controle social, responsável pela aplicação da lei”.

Quanto aos direitos sociais tratou da inclusão social, laboral e produtiva do migrante por meio de políticas públicas; acesso igualitário e livre do imigrante a serviços, programas e benefícios sociais, bens públicos, educação, assistência jurídica integral pública, trabalho, moradia, serviço bancário e seguridade social.

${ }^{13}$ Idem: "Conforme demonstram diversos exemplos ao redor do mundo, são ineficazes todas as tentativas de contençáo dos fluxos migratórios pela via repressiva de endurecimento do controle fronteiriço. Apertar o controle serve apenas para incentivar meios alternativos como os coiotes, que aumentam ainda mais os abusos contra os migrantes e instigam insegurança para a população em geral.” 
Não por acaso é que a referida Lei passou a ser alvo de elogios ${ }^{14}$ e também de ataques ${ }^{15}$ por parte de vários segmentos da sociedade brasileira. Apesar de toda carga de "paixão" existente para aqueles que defendem e para os que atacam a nova Lei, o fato é que a matéria corresponde a um grande avanço neste campo.

\section{A ADMISSÃO E A RETIRADA COMPULSÓRIA DO MIGRANTE}

$\mathrm{O}$ ato de ingresso e permanência do estrangeiro em território nacional relaciona-se à discricionariedade do Estado, podendo este aceitar ou náo que uma determinada pessoa permaneça em seu território, como no caso em que um

${ }^{14} \mathrm{O}$ senador Tasso Jereissati (PSDB-CE) afirmou, em entrevista à Rádio Senado, que o projeto da nova Lei de Migração tem uma "visăo nova" sobre os estrangeiros no Brasil. A ideia, disse ele, é garantir direitos para que o imigrante possa trabalhar e contribuir para o crescimento do país. Segundo o senador, o texto aprovado recentemente pelo Senado depois das alteraçóes feitas pela Câmara dos Deputados (SCD 7/2016) muda a "visão econômica" do Estatuto do Estrangeiro (Lei 6.815/80). Disponível em http://www12.senado.leg.br/noticias/audios/2017/04/tasso-nova-lei-de-migracao-da-ao-estrangeiro-oportunidade-de-contribuir-para-o-brasil Acesso em 06 de maio de 2017.

${ }^{15}$ No dia 26 de março de 2017 a direita saiu às ruas em todo o Brasil. Apesar de os protestos terem sido convocados com o intuito de defender a Reforma da Previdência, apareceu uma miríade de pautas, que iam desde questóes econômicas até questóes de cunho moral. Surgiram pontos como a defesa da Reforma da Previdência, do direito irrestrito de portar armas, da operação Lava Jato, da Polícia Federal, além da proibição do financiamento público de campanhas e contra a nova Lei de Migração. Em tempos de crise (social, econômica e política, em nosso caso) é sempre conveniente encontrar um bode expiatório para os problemas do país. Nesses casos, a suposta culpa recai sobre os grupos mais vulneráveis da sociedade, como imigrantes, mulheres, negros e LGBTs. Apesar de o Brasil não estar recebendo um número elevado de imigrantes e refugiados, a narrativa do "estrangeiro" como um perigo começa a ressurgir por aqui, justo quando o país está prestes a modificar sua legislação migratória. (...) Ávidos por encontrar um culpado para as nossas crises, esses grupos conservadores buscam despertar nas pessoas o sentimento de medo. No ato do dia 26 de março, uma liderança desses grupos, falando no carro de som em plena Avenida Paulista, afirmou que a nova Lei de Migração "escancara nossas fronteiras e coloca para dentro quem quiser entrar". Acrescentou ainda que isso irá sobrecarregar os serviços públicos - como se fossem os migrantes os responsáveis pela má qualidade dos serviços públicos no Brasil, historicamente negligenciados pelo poder público. Essa liderança disse também que, no período de um ano, irá entrar no país uma quantidade de "estrangeiros" equivalente à atual população brasileira e que isso poderá até modificar a língua materna - sem apresentar dados que de fato embasem essas afirmaçóes. O elemento novo dessa narrativa - muito comum em discursos xenófobos - é que agora estão dizendo que "os fluxos migratórios ocorrem porque o Partido dos Trabalhadores (PT) teria perdido maioria e que estaria tentando importar pessoas para compor uma nova maioria”. Disponível em http://migramundo.com/nova-lei-de-migracao-e-migrantes-sob-ataque-um-relato-dos-protestos-de-26-de-marco-no-brasil/ Acesso em 6 de maio de 2017. 
indivíduo tenha atentado contra a segurança do Estado (como na prática de atos terroristas). Há de ressaltar que o Estado não pode se prender a questôes relativas à raça, sexo, idioma ou religião.

É de competência exclusiva de cada Estado legislar sobre a admissão e expulsão de estrangeiros em sua base física. Deste modo, várias são as restriçóes que os Estados adotam no tocante à admissão de estrangeiros em seu território. Uns cobram taxas de admissão, outros fixam cota de imigraçáo e quase todos exigem a apresentação de passaporte.

A Lei 13.445/2017 também dispôs sobre esta matéria, entretanto, diferentemente da lei do estrangeiro, procura apresentar critérios objetivos que garantem, de forma mais satisfatória, proteção jurídica ao não nacional.

Para ser admitido em território brasileiro o migrante ${ }^{16}$ deverá ter em sua posse um documento que o identifique. A nova legislação admite como documentos de viagem o passaporte; o laissez-passer; a autorização de retorno; o salvo-conduto; a carteira de identidade de marítimo; a carteira de matrícula consular; o documento de identidade civil ou documento estrangeiro equivalente, quando admitidos em convenção ou tratado internacional; o certificado de membro de tripulação de transporte aéreo e outros que vierem a ser reconhecidos pelo Estado brasileiro em regulamento.

A nova lei apresenta o visto como o documento que dá a seu portador expectativa de ingresso em território nacional (Artigo $6^{\circ}$ ), podendo ser expedido por embaixadas, consulados-gerais, consulados, vice-consulados e, quando habilitados pelo órgáo competente do poder Executivo, por escritórios comerciais e de representação do Brasil no exterior (Artigo 7º). Assim, serão concedidos pelo Estado brasileiro ao solicitante que pretenda ingressar ou permanecer no território

\footnotetext{
${ }^{16}$ Os artigos $10^{\circ}$ e 11 versam sobre a não concessão do visto: "Art. $10^{\circ}$. Não se concederá visto: I - a quem náo preencher os requisitos para o tipo de visto pleiteado; II - a quem comprovadamente ocultar condição impeditiva de concessão de visto ou de ingresso no País; ou III - a menor de 18 (dezoito) anos desacompanhado ou sem autorização de viagem por escrito dos responsáveis legais ou de autoridade competente. Art. 11. Poderá ser denegado visto a quem se enquadrar em pelo menos um dos casos de impedimento definidos nos incisos I, II, III, IV e IX do art. 45. Parágrafo único. A pessoa que tiver visto brasileiro denegado será impedida de ingressar no país enquanto permanecerem as condiçốes que ensejaram a denegação."
} 
nacional, os seguintes tipos de vistos: visita; temporário; diplomático; oficial e de cortesia (artigo 12), podendo ser cobrados taxas e emolumentos consulares pelo processamento do visto.

No caso do apátrida, tema que tem sido objeto de reflexóes no âmbito do Direito Internacional, a seção II da Lei n. 13.445/2017 conferiu proteção para o apátrida. A matéria, todavia, ainda deverá ser regulamentada, conforme estabelece o Artigo 26, para que possa garantir proteçáo especial, bem como seja consolidado processo simplificado de naturalização. Neste caso, o processo de que trata o referido artigo será iniciado tão logo seja reconhecida a situação de apatridia, sendo certo que durante a tramitação do processo de reconhecimento da condição de apátrida incidem todas as garantias e mecanismos protetivos e de facilitação da inclusão social relativos à Convenção sobre o Estatuto dos Apátridas de 1954, promulgada pelo Decreto no 4.246, de 22 de maio de 2002, à Convençáo relativa ao Estatuto dos Refugiados, promulgada pelo Decreto no 50.215, de 28 de janeiro de 1961, e à Lei no 9.474, de 22 de julho de 1997.

Impende assinalar que são aplicados ao apátrida residente todos os direitos atribuídos ao migrante relacionados no artigo $4^{\circ}$ da Lei $13.445 / 2017$, sendo assegurados os direitos e garantias previstos na Convenção sobre o Estatuto dos Apátridas, de 1954, promulgada pelo Decreto no 4.246, de 22 de maio de 2002, bem como outros direitos e garantias reconhecidos pelo Brasil.

Com efeito, o processo de reconhecimento da condição de apátrida tem como objetivo verificar se o solicitante é considerado nacional pela legislação de algum Estado e poderá considerar informaçóes, documentos e declaraçóes prestadas pelo próprio solicitante e por órgãos e organismos nacionais e internacionais. Sendo reconhecida a condição de apátrida, nos termos do inciso VI do $\$ 1^{\circ}$ do Artigo $1^{\circ}$, o solicitante será consultado sobre o desejo de adquirir a nacionalidade brasileira e caso o apátrida opte pela naturalização, a decisáo sobre o reconhecimento será encaminhada ao órgão competente do poder Executivo para publicação dos atos necessários à efetivação da naturalização no prazo de 30 dias. Por fim, vale destacar que o apátrida reconhecido que não opte pela naturalização imediata terá a autorização de residência outorgada em caráter definitivo e apenas deixará de ter a proteção do Estado brasileiro, conferida pela Lei 13.445/2017, nos casos de renúncia; prova da falsidade dos fundamentos invocados para o reconhecimento 
da condiçáo de apátrida; ou a existência de fatos que, se fossem conhecidos por ocasião do reconhecimento, teriam ensejado decisão negativa. Quanto ao asilo, que pode ser territorial ou diplomático, a lei também dispôs sobre a matéria como sendo um instrumento protetivo à pessoa humana, não sendo concedido para quem tenha cometido crime de genocídio, crime contra a humanidade, crime de guerra ou crime de agressáo, nos termos do Estatuto de Roma do Tribunal Penal Internacional, de 1998. ${ }^{17}$

Uma vez admitido em território nacional, o indivíduo18 estará sujeito às leis locais, observando-se situaçôes excepcionais correspondentes às imunidades concebidas nos documentos internacionais. A lei também estabeleceu em que circunstâncias o indivíduo não será aceito no território nacional, conforme preceitua o artigo 45: "Poderá ser impedida de ingressar no país, após entrevista individual e mediante ato fundamentado, a pessoa: I - anteriormente expulsa do país, enquanto os efeitos da expulsão vigorarem; II - condenada ou respondendo a processo por ato de terrorismo ou por crime de genocídio, crime contra a humanidade, crime de guerra ou crime de agressão, nos termos definidos pelo Estatuto de Roma do Tribunal Penal Internacional, de 1998, promulgado pelo Decreto no 4.388, de 25 de setembro de 2002; III - condenada ou respondendo a processo em outro país por crime doloso passível de extradição segundo a lei brasileira; IV - que tenha o nome incluído em lista de restriçóes por ordem judicial ou por compromisso assumido pelo Brasil perante organismo internacional; $\mathrm{V}$ - que apresente documento

${ }^{17}$ A matéria está no capítulo XIII do livro de GUERRA, Sidney. Curso de direito internacional público. 10. ed. São Paulo: Saraiva, 2016.

${ }^{18} \mathrm{O}$ artigo 30, incisos I e II, apresentam os casos em que podem ser autorizadas a residência do imigrante, residente fronteiriço ou visitante. Art. 30. A residência poderá ser autorizada, mediante registro, ao imigrante, ao residente fronteiriço ou ao visitante que se enquadre em uma das seguintes hipóteses: I - a residência tenha como finalidade: a) pesquisa, ensino ou extensão acadêmica; b) tratamento de saúde; c) acolhida humanitária; d) estudo; e) trabalho; f) férias-trabalho;g) prática de atividade religiosa ou serviço voluntário; h) realização de investimento ou de atividade com relevância econômica, social, científica, tecnológica ou cultural; i) reunião familiar; II - a pessoa: a) seja beneficiária de tratado em matéria de residência e livre circulação; b) seja detentora de oferta de trabalho; c) já tenha possuído a nacionalidade brasileira e nấo deseje ou não reúna os requisitos para readquiri-la; d) (vetado); e) seja beneficiária de refúgio, de asilo ou de proteção ao apátrida; f) seja menor nacional de outro país ou apátrida, desacompanhado ou abandonado, que se encontre nas fronteiras brasileiras ou em território nacional; g) tenha sido vítima de tráfico de pessoas, de trabalho escravo ou de violaçáo de direito agravada por sua condição migratória; h) esteja em liberdade provisória ou em cumprimento de pena no Brasil. 
de viagem que: a) não seja válido para o Brasil; b) esteja com o prazo de validade vencido; ou c) esteja com rasura ou indício de falsificação; VI - que não apresente documento de viagem ou documento de identidade, quando admitido; VII - cuja razão da viagem não seja condizente com o visto ou com o motivo alegado para a isenção de visto; VIII - que tenha, comprovadamente, fraudado documentação ou prestado informação falsa por ocasião da solicitação de visto, ou IX - que tenha praticado ato contrário aos princípios e objetivos dispostos na Constituição Federal.”

Com efeito, da mesma forma que o Estado pode acolher um indivíduo de nacionalidade distinta dos seus, também poderá retirá-lo. A matéria, na nova legislação, vem expressa no capítulo VI que versa sobre as medidas de retirada compulsória.

A primeira medida que poderá ser adotada pelo Estado é a repatriação, que consiste na devolução de pessoa em situação de impedimento ao país de procedência ou de nacionalidade, sendo certo que tal medida não será aplicada para pessoa em situação de refúgio ou de apatridia, de fato ou de direito; aos menores de 18 anos desacompanhados ou separados de suas famílias, exceto nos casos em que se demonstrar favorável; para a garantia de seus direitos ou para a reintegração a sua família de origem, ou a quem necessite de acolhimento humanitário; nem, em qualquer caso, de devolução para país ou região que possa apresentar risco a sua vida, integridade pessoal ou liberdade.

Ainda no capítulo VI, nas seções de números III e IV, a legislação contemplou aspectos relativos à deportação e expulsão, respectivamente. Antes, porém, de apresentá-los, importante frisar que a nova lei ao consagrar princípios e diretrizes que devem pautar o desenvolvimento da matéria no Brasil, garantiu a náo criminalização por razóes migratórias, isto é, independentemente do motivo pelo qual se deu a mesma, o indivíduo não estará sujeito à deportação, bem como não poderá ter a sua liberdade cerceada por não estar de posse de sua documentação, diferentemente do que acontecia sob a égide da lei do estrangeiro. Sobre este ponto, há estudos que indicam que a efetivação desta matéria será um grande desafio, principalmente nos controles que são realizados em zonas de fronteira e a incidência de deportaçóes arbitrárias, como se vê: 
"Para ilustrar, podemos citar casos recentes ocorridos no Estado de Roraima - localizado na fronteira do Brasil com Venezuela e Guiana - quando venezuelanos foram deportados pela polícia ao longo do ano de 2016, mesmo aqueles que solicitaram o refúgio. Uma ação judicial impediu que 450 venezuelanos fossem coletivamente deportados no mês de dezembro daquele ano. Há, ademais, casos de repatriaçáo em que migrantes são colocados em um limbo jurídico e mantidos em áreas de fiscalização, a exemplo do chamado "espaço Conector" do Aeroporto Internacional de Guarulhos, São Paulo, arbitrariamente e por tempo indeterminado, sem a assistência necessária e a garantia do devido processo legal, até conseguirem verbalizar um pedido de refúgio ou serem devolvidos para o país de origem. De janeiro de 2015 até abril de 2016, 1.814 migrantes foram mantidos no "espaço Conector”, dos quais 494 eram solicitantes de refúgio que procuravam proteção no país e foram impedidos de ingressar diretamente em solo brasileiro. Importante frisar que neste ponto, pessoas em situação de refúgio náo podem ser devolvidas para o país de origem por conta da sua vida estar em risco, de acordo com o princípio fundamental de non-refoulement (não devolução) do Direito Internacional Público e conforme consta na legislação brasileira que trata do refúgio (Lei 9.474/1997).”"19

A propósito, quanto ao residente fronteiriço, para facilitar sua livre- circulação, o Estado poderá conceder autorização para a realização de atos da vida civil, mediante requerimento do interessado. Esta medida foi bastante adequada, principalmente se forem levadas em conta as extensas fronteiras do Estado brasileiro com os países da América do Sul (exceçáo do Equador e Chile apenas). Assim, o residente fronteiriço detentor da autorização gozará das garantias e dos direitos assegurados pelo regime geral de migraçáo da nova Lei, podendo ser cancelado, a qualquer tempo, se o titular tiver fraudado documento ou utilizado documento falso para obtê-lo; obtiver outra condição migratória; sofrer condenação penal ou exercer direito fora dos limites previstos na autorização.

No caso da deportação, esta ocorre quando se promove a retirada do imigrante que, ingressando no país ou neste se encontrando irregularmente, não sair voluntariamente no prazo que lhe for determinado. Trata-se, portanto, de medida decorrente de procedimento administrativo que consiste na retirada compulsória de

${ }^{19}$ ASANO, Camila Lissa; TIMO, Pétalla Brandão, op. cit. 
indivíduo que se encontre em situação migratória irregular em território nacional. Para tanto, a deportação será precedida de notificação pessoal ao imigrante, na qual constem, expressamente, as irregularidades verificadas e prazo para a regularização náo inferior a 60 dias, podendo ser prorrogado, por igual período, por despacho fundamentado e mediante compromisso de o imigrante manter atualizadas suas informações domiciliares

Impende assinalar que no caso de incidência da deportação não haverá por parte do indivíduo o cometimento de crime e sim a náo observância de determinados requisitos legais para sua permanência no Estado. A nova lei inovou ao dispor que mesmo sendo notificado o indivíduo não ficará impedido de circular livremente no território nacional, devendo, todavia, o imigrante informar seu domicílio e suas atividades. Apenas com o vencimento do prazo para que ele regularize sua situação com o Estado brasileiro, observando-se o princípio constitucional do contraditório e ampla defesa, é que a deportação poderá ser executada, não excluindo eventuais direitos adquiridos ao deportado, em relaçóes contratuais ou decorrentes da lei brasileira. ${ }^{20}$

No caso da expulsão, a nova legislação a trata como medida administrativa de retirada compulsória do migrante do território nacional, conjugada com o impedimento de reingresso por prazo determinado, sendo certo que a condenação com sentença transitada em julgado poderá ensejar a expulsão nos seguintes casos: crime de genocídio, crime contra a humanidade, crime de guerra ou crime de agressão, nos termos definidos pelo Estatuto de Roma do Tribunal Penal Internacional, de 1998; crime comum doloso passível de pena privativa de liberdade, consideradas a gravidade e as possibilidades de ressocialização em território nacional.

\footnotetext{
${ }^{20}$ Importante destacar o papel da Defensoria Pública da União em situações que versem sobre a deportação: "Art. 51. Os procedimentos conducentes à deportação devem respeitar o contraditório e a ampla defesa e a garantia de recurso com efeito suspensivo. $\$ 1$ o A Defensoria Pública da União deverá ser notificada, preferencialmente por meio eletrônico, para prestação de assistência ao deportando em todos os procedimentos administrativos de deportaçáo". $\$ 2$ o A ausência de manifestação da Defensoria Pública da União, desde que prévia e devidamente notificada, não impedirá a efetivação da medida de deportação."
} 
Por outro lado, são apresentados os casos que não são passíveis de expulsão, a saber: se implicar extradição inadmitida pela lei brasileira; e quando o expulsando tiver filho brasileiro que esteja sob sua guarda ou dependência econômica ou socioafetiva ou tiver pessoa brasileira sob sua tutela; tiver cônjuge ou companheiro residente no Brasil, sem qualquer discriminação, reconhecido judicial ou legalmente; tiver ingressado no Brasil até os 12 anos de idade, residindo desde então no país; for pessoa com mais de 70 anos que resida no país há mais de 10 anos, considerados a gravidade e o fundamento da expulsão, ou estiver vivendo no Brasil há mais de 4 anos anteriores ao cometimento do crime..$^{21}$

Ao que parece, a nova lei ${ }^{22}$ brasileira, inspirada em princípios como o da não indiferença, ${ }^{23}$ começa a atribuir o valor e importância para aqueles que, por motivos diversos, acabaram por deixar o seu país de origem.

${ }^{21}$ Os artigos 58, 59 e 60 também apresentam aspectos importantes sobre a expulsão: Art. 58. No processo de expulsão serão garantidos o contraditório e a ampla defesa. $\$ 1$ o A Defensoria Pública da União será notificada da instauração de processo de expulsão, se não houver defensor constituído. $\$$ 2o Caberá pedido de reconsideração da decisão sobre a expulsão no prazo de 10 (dez) dias, a contar da notificação pessoal do expulsando. Art. 59. Será considerada regular a situação migratória do expulsando cujo processo esteja pendente de decisão, nas condiçôes previstas no art. 55. Art. 60. A existência de processo de expulsão não impede a saída voluntária do expulsando do país.

${ }^{22}$ A lei 13.445/2017 contempla vários outros aspectos. Por exemplo, o Capítulo VI versa sobre a opção de nacionalidade e da naturalização; o Capítulo VII trata do emigrante; o Capítulo VIII abarca as medidas de cooperação; o Capítulo IX versa sobre as infraçóes e as penalidades administrativas; além de outras matérias. Neste tópico do livro, todavia, priorizou-se apresentar as questóes gerais sobre a nova lei e, posteriormente será apresentado estudo específico sobre a lei de migraçóes como um todo.

${ }^{23}$ Como na obra de GUERRA, Sidney. Curso de direito internacional público. 10. ed. São Paulo: Saraiva, 2016. 


\section{CONSIDERAÇÕES FINAIS}

A situação atual dos imigrantes que se apresenta atualmente no mundo é dramática e tem produzido uma crise sem precedentes em vários setores, quando por vezes coloca-se em dúvida a solidariedade, a compaixão, aspectos morais, o valor que deve ser atribuído ao Direito e o papel dos direitos humanos na sociedade atual. Na Europa ${ }^{24}$ por exemplo, o número de refugiados que já se arriscaram pelo mar, apenas no ano de 2017, para aportar em solo europeu pelo caminho italiano, ultrapassou o número de 43 mil pessoas e isso tem gerado um grande desconforto por parcela significativa dos cidadáos europeus. ${ }^{25}$ Os dados podem ser mais bem observados a seguir:

${ }^{24}$ Os dados foram divulgados pelo alto-comissário da ONU para Refugiados, Filippo Grandi, que alertou para as mortes e desaparecimentos, registrados desde o início do ano, de mais de 1,1 mil indivíduos durante a travessia. "A rota da regiáo central do mar Mediterrâneo, entre o norte da África e a Itália, um dos caminhos mais usados pelos solicitantes de refúgio e pelos migrantes que vão para a Europa, se provou particularmente fatal. Disponível em: <https://nacoesunidas.org/tema/refugiados-migrantes/>. Acesso em: 17 maio 2017.

${ }^{25}$ A Revista Isto É publica uma pesquisa realizada na Europa que apresenta dados estarrecedores sobre a visão que muitos europeus possuem sobre o fenômeno migratório, em especial em relação aos islâmicos. A matéria, em tom sensacionalista, apresenta o título "A Europa contra os imigrantes". Disponível em: $<$ http://istoe.com.br/europa-contra-os-imigrantes>. Acesso em: 17 maio 2017: Em recente pesquisa elaborada na União Europeia, na qual se pergunta se deveriam ser adotadas medidas de contenção para que não ocorra a migração de maneira tão intensa e se a imigração de naçóes predominantemente islâmicas deveria ser barrada, verificou-se que mais da metade dos habitantes do Velho Continente concorda com o veto. Apesar de o sentimento contra refugiados ser mais intenso na Áustria, Bélgica, França, Hungria e Polônia, mesmo os lugares mais tolerantes apresentam índices extremamente altos de xenofobia. Entre os países consultados, a Espanha é o que tem a população mais aberta. Mesmo assim, $41 \%$ concordam que a entrada de imigrantes vindos de naçôes muçulmanas deveria acabar. Em nenhum local, mais de um terço discorda. Os achados também revelam como o anti-islamismo é especialmente intenso entre os mais velhos (60\%), os menos educados $(59 \%)$ e os que vivem no campo (58\%). Os números, no entanto, ainda ficam perto da metade entre os mais novos, mais educados e que vivem nas cidades. "Na maioria dos Estados onde a oposição é forte, a direita radical está entranhada como uma força política e busca mobilizar essa angústia contra o Islã nas urnas", afirma o relatório da pesquisa, realizada pelo instituto de relações internacionais Chatam House. 


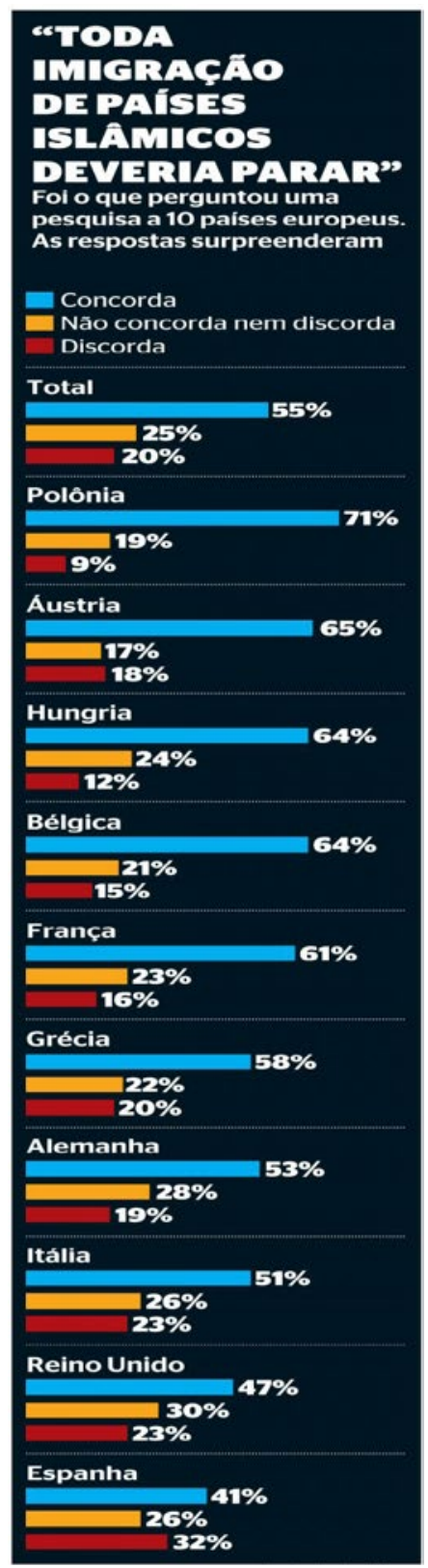

Fonte: Instituto de Relações Internacionais Chatam House. 
Apesar de tudo isso, recentemente a grande preocupação que pairava no Velho Continente, com a possível eleição presidencial de uma candidata da extrema direita (na França) e seus desdobramentos, foi superada. Novamente o sentimento das milhares de pessoas que se encontram na situação de não nacionais europeus, mas que almejam um local seguro para passarem suas vidas, é de esperança.

Aqui no Brasil a matéria sofreu mudanças bastante significativas, haja vista que era regida pela Lei 6.815/80, que considerava o estrangeiro um assunto de segurança nacional e dava ao Estado a possibilidade de decidir ao seu bel-prazer quem poderia entrar e permanecer no Brasil. A norma era incompatível com a Constituição Federal e os tratados internacionais de direitos humanos, tendo sido substituída pela Lei 13.445/2017, que passou a considerar os migrantes como tema de direitos humanos, encorajando a regularização migratória e conferiu ao imigrante a oportunidade de ser incluído socialmente.

Diante de um cenário obscuro, preocupante, tenso e indiferente pelo qual passa o mundo, com tantos conflitos e violaçóes aos direitos humanos, o Estado brasileiro, que preconiza a dignidade da pessoa humana como princípio fundamental, bem como a prevalência dos direitos humanos, concebe a nova Lei de Migração em excelente hora, plenamente em consonância com o princípio da não indiferença, que se propóe a servir como axioma para a construçáo de uma sociedade que seja cada vez mais justa, inclusiva e protetiva dos direitos inerentes à pessoa humana.

\section{REFERÊNCIAS}

ASANO, Camila Lissa; TIMO, Pétalla Brandão. A nova Lei de migração no Brasile os direitos humanos. Disponível em: <https://br.boell.org/pt-br/2017/04/17/nova-lei-de-migracao-no-brasil-e-os-direitos-humanos>. Acesso em: 3 maio 2017.

ESTATÍSTICA SOBRE OS ESTRANGEIROS. Disponível em: <http://www.pf.gov.br/ imprensa/estatistica/estrangeiros>. Acesso em: 16 maio 2017.

GIDDENS, Anthony. O mundo na era da globalização. Lisboa: Presença, 2000.

GRANDI, Filippo. Disponível em: <https://nacoesunidas.org/tema/refugiados-migrantes/>. Acesso em: 17 maio 2017. 
GUERRA, Sidney. Os direitos humanos na ordem juridica internacional e reflexos para ordem constitucional brasileira. Rio de Janeiro: Lumen Juris, 2008a.

. Tratado de direito internacional. Rio de Janeiro: Freitas Bastos, 2008b.

. Curso de direito internacional público. 10. ed. São Paulo: Saraiva, 2016.

REVISTA ISTO É. A Europa contra os imigrantes. Disponível em: <http://istoe.com.br/europa-contra-os-imigrantes/>. Acesso em: 17 maio 2017.

REZEK, José Francisco Direito internacional público: curso elementar. 6. ed. São Paulo: Saraiva, 1996.

VERDÚ, Pablo Lucas. O sentimento constitucional: aproximaçóes ao estudo do sentir constitucional como modo de integração política. Rio de Janeiro: Forense, 2004. 